\title{
OPEN Strain hardening recovery mediated by coherent precipitates in lightweight steel
}

\author{
Sung-Dae Kim ${ }^{1}$, Seong-Jun Park ${ }^{1}$, Jae hoon Jang ${ }^{1}$, Joonoh Moon ${ }^{1}$, Heon-Young Ha ${ }^{1}$, \\ Chang-Hoon Lee ${ }^{1}$, Hyungkwon Park ${ }^{1}$, Jong-Ho Shin ${ }^{2}$ \& Tae-Ho Lee ${ }^{1 \bowtie}$
}

We investigated the effect of $\mathrm{K}$-carbide precipitates on the strain hardening behavior of aged $\mathrm{Fe}-$ $\mathrm{Mn}-\mathrm{Al}-\mathrm{C}$ alloys by microstructure analysis. The $\mathrm{k}$-carbides-strengthened $\mathrm{Fe}-\mathrm{Mn}-\mathrm{Al}-\mathrm{C}$ alloys exhibited a superior strength-ductility balance enabled by the recovery of the strain hardening rate. To understand the relation between the $\mathrm{k}$-carbides and strain hardening recovery, dislocation gliding in the aged alloys during plastic deformation was analyzed through in situ tensile transmission electron microscopy (TEM). The in situ TEM results confirmed the particle shearing mechanism leads to planar dislocation gliding. During deformation of the $100 \mathrm{~h}$-aged alloy, some gliding dislocations were strongly pinned by the large $\mathrm{k}$-carbide blocks and were prone to cross-slip, leading to the activation of multiple slip systems. The abrupt decline in the dislocation mean free path was attributed to the activation of multiple slip systems, resulting in the rapid saturation of the strain hardening recovery. It is concluded that the planar dislocation glide and sequential activation of slip systems are key to induce strain hardening recovery in polycrystalline metals. Thus, if a microstructure is designed such that dislocations glide in a planar manner, the strain hardening recovery could be utilized to obtain enhanced mechanical properties of the material.

A class of high-Mn steels provides an alternative way to increase their specific strength by reducing their specific weight, leading them to be known as "lightweight steels"1-4. Lightweight steels are realized by adding the characteristic light element, i.e., Al, where $1 \mathrm{wt}$. \% reduces the specific weight of steels by approximately $1.5 \mathrm{wt} . \%^{2-4}$. This alloy system is characterized by a high content of $\mathrm{Mn}(18-30 \mathrm{wt} . \%)$ and $\mathrm{Al}$ (<12 wt.\%) along with $\mathrm{C}(0.6-1.8$ $\mathrm{wt} . \%)^{1-18}$. In particular, the addition of $\mathrm{Al}$ to the alloys not only promotes weight reduction, but also improves their mechanical properties. The alloys exhibit a superior strength-ductility balance enabled by their unusual strain hardening behavior ${ }^{1-4,6-11,13,15,17,18}$. Furthermore, in contrast to ordinary malleable metals, where the strain hardening rate monotonically decreases during tensile deformation ${ }^{19-24}$, the Al-containing high-Mn steels (Fe-Mn-Al-C alloys) show a considerable recovery in the hardening rate with plastic deformation ${ }^{2,4,6,7,9,11,16-18}$. Such a strain hardening recovery or secondary strain hardening can significantly improve the ultimate tensile strength and ductility by delaying the necking point up to a higher strain level ${ }^{22,24}$.

Previous studies on the strain hardening recovery in polycrystalline materials attributed the recovery to their characteristic planar slip behavior. Yang et al. ${ }^{25}$ reported that strain hardening recovery occurs in polycrystalline $\mathrm{Ni}$-Si alloys with large grain sizes. Via detailed microstructural characterizations, they showed that the planar dislocation slip leads to sequential activation of the secondary slip systems during tensile deformation. Thus, a sharp decrease in the dislocation mean free path (L) during the activation of the secondary slip systems is the primary reason for the strain hardening recovery. Recently, the slip activity-based strain hardening (SASH) model $^{26}$ was proposed, considering the strain-dependent orientation factor, which spans from the lower-bound iso-stress Sachs model to the upper-bound iso-strain Taylor model. The SASH model successfully predicts the strain hardening recovery in polycrystalline metals with the presence of shearable precipitates, supporting that strain hardening recovery is a result of the planar slip-induced sequential activation of the slip systems.

Therefore, the strain hardening recovery of Fe-Mn-Al-C alloys can also be attributed to their characteristic planar slip behavior. Earlier seminal investigations $s^{1-4,6-18,27}$ have demonstrated that the deformation of the Fe-Mn-Al-C alloy mainly occurs due to the pronounced planar slip, which is strongly correlated to the ordered second phase, namely, $\kappa$-carbide precipitates. Adding Al promotes the formation of a fine distribution

\footnotetext{
${ }^{1}$ Advanced Metals Division, Korea Institute of Materials Science, 797 Changwondaero, Changwon 51508, Republic of Korea. ${ }^{2}$ Materials and Manufacturing Technology Development Center, Corporate Research and Development Institute, Doosan Heavy Industries and Construction Co. LTD, 22 Doosanvolvo-ro, Changwon, Gyeongnam 51711, Republic of Korea. ${ }^{\bowtie}$ email: Ith@kims.re.kr
} 
of nanometer-sized L' $1_{2}$ atomic ordering (short-range ordering (SRO) or long-range ordering (LRO)) with an $(\mathrm{Fe}, \mathrm{Mn})_{3} \mathrm{AlC}_{\mathrm{x}}(\mathrm{x} \leq 1)$ stoichiometry via spinodal decomposition ${ }^{5,12,28,29}$. Further, the ordered regions evolve into $\kappa$-carbide precipitates during aging at $500-650{ }^{\circ} \mathrm{C}$. Since the ordered precipitates have a similar atomic structure as the disordered matrix, the $\kappa$-carbides can be considered as modified face-centered cubic (FCC) structures, where $\mathrm{Al}$ atoms substitute the $\mathrm{Fe}$ atoms at the corner sites of the austenite unit cell. Based on this structural similarity, the $\kappa$-carbides are coherent or semi-coherent with the disordered austenite matrix, possessing a lattice misfit below $2 \%{ }^{15,16,18}$. Although the exact origin for this planar glide is disputed ${ }^{1,3,6,7,9,11,14-16,18}$, a consensus has been reached that the "glide plane softening" phenomenon induces the planar glide ${ }^{2,4}$. In glide plane softening, the shearing of the resistive second phase (or precipitates) by leading dislocations enables the succeeding dislocations to easily glide on the same plane.

Thus, it is conceivable that the strain hardening recovery of Fe-Mn-Al-C alloys is inevitably dependent on the $\kappa$-carbide precipitation state. However, an understanding of the relation between the $\kappa$-carbide precipitates and the dislocation gliding behavior in the alloys is not yet firmly established. Furthermore, a clear interpretation of the strain hardening recovery mechanism based on dislocation plasticity is still missing. To address these gaps, the present investigation analyzes the effect of $\kappa$-carbide precipitates on the dislocation glide via in situ transmission electron microscopy (TEM), focusing on the interactions between the precipitates and gliding dislocations. Further, an attempt is made to understand the role of microstructural factors in the strain hardening behavior of Al-containing high-Mn lightweight steels using the experimental results.

\section{Results}

Precipitation state. Figure 1 shows the representative precipitation states of the $\mathrm{Fe}-\mathrm{Mn}-\mathrm{Al}-\mathrm{C}$ alloys after isothermal aging at $600{ }^{\circ} \mathrm{C}$ for various durations. The selected area diffraction patterns (SADPs, Fig. 1a) taken from the $24 \mathrm{~h}$-aged sample reveal that the $\kappa$-carbides have a cube-cube orientation relationship (OR) with the austenite matrix. Figure 1c-f shows the dark-field (DF) TEM images of the $\kappa$-carbides, which were acquired using the (001) superlattice spot in the SADP (Fig. 1a). The DF TEM images (Fig. 1c-f) show that the morphology of the $\kappa$-carbides is rectangular with $\{001\}$ habit planes, similar to that of $\gamma / \gamma^{\prime}\left(\mathrm{Ni}_{3} \mathrm{Al}\right)$ in Ni-base superalloys $^{30-33}$. The development of such a unique morphology is attributed to the preferential growth of the coherent $\{001\} \kappa^{-}{ }_{\text {carbide }} / /\{001\}_{\text {austenite }}$ interface to minimize the surface energy. The mean diameters of the precipitates in the 1,3,24, and $100 \mathrm{~h}$-aged samples were measured as 5, 8, 16, and $44 \mathrm{~nm}$, respectively (Fig. 1b). As the aging time increases, the arrangement of $\kappa$-carbides changes from a random dispersion (Fig. 1c) to aligned stacks (Fig. 1d-f), i.e., the austenite matrix regions between the $\kappa$-carbides are categorized into narrow and wide channels. Previous atom probe tomography (APT) analysis ${ }^{16,18,27}$ has reported that most $\kappa$-carbides were grown into rectangular parallelepipeds rather than a cuboidal morphology, following which the carbide plates were aligned into "particle stacks" along the orthogonal $<001>$ direction. High-angle annular dark-field (HAADF) STEM images of the $24 \mathrm{~h}$-aged alloy acquired along a $<001>$ direction (Fig. 2) visualized the coherent interface between the precipitate and austenite matrix. Further, the $\kappa$-carbides could be distinguished by the Al columns from the disordered matrix (Fig. 2b) because the light elements reduce the intensity of the HAADF-STEM image (Z-contrast) ${ }^{34-36}$. Geometric phase analysis (GPA) ${ }^{37,38}$ of the 24 h-aged Fe-Mn-Al-C alloy (Fig. 3) was conducted to estimate the misfit strain in the vicinity of the $\kappa$-carbides. The $\varepsilon_{\mathrm{xx}}$ (Fig. $3 \mathrm{~b}$ ) and $\varepsilon_{\mathrm{yy}}$ (Fig. $3 \mathrm{c}$ ) maps show that compressive strains $(<3 \%)$ are imposed on the narrow $\gamma$ channels, whereas tensile strains $(<2 \%)$ are exerted on the $\kappa$-carbides. Accordingly, shear strains $\left(\varepsilon_{\mathrm{xy}}\right)$ are intensively developed between the narrow $\gamma$ channels (Fig. 3d). Nevertheless, it appears that the mean values of the strains are not large enough to generate misfit dislocations, revealing that the carbides are fully coherent with the matrix.

Mechanical properties. Figure 4a,b show the true stress-strain curves of the aged alloys and corresponding strain hardening rate curves measured at $293^{\circ} \mathrm{C}$ respectively. Even after aging at $600{ }^{\circ} \mathrm{C}$ for $3 \mathrm{~h}$, the yield strength (YS) of the alloys significantly increased (71\%, $780 \mathrm{MPa})$ compared to that of the as-solution (AS) alloy (455 MPa). This high level of YS was maintained up to $24 \mathrm{~h}$ aging $(800 \mathrm{MPa})$, and decreased to $706 \mathrm{MPa}$ after $100 \mathrm{~h}$. The decrease in YS after $100 \mathrm{~h}$ of aging can be attributed to the existence of a precipitate-free zone (PFZ) near the grain boundaries ${ }^{8,39,40}$, (Fig. 4c). Although the precipitates harden the matrix of the $100 \mathrm{~h}$ alloy, the relatively soft PFZ enables the initiation of the plastic deformation, leading to a reduction in YS. Furthermore, the maximum elongation is decreased as the aging time increases $(43,41$, and $39 \%$ after $3 \mathrm{~h}, 24 \mathrm{~h}$, and $100 \mathrm{~h}$, respectively). The strain hardening rate curves of the alloys (Fig. 4b) exhibit humps, revealing that the strain hardening "recovery" occurs after a sharp drop at the yield point. As the aging time increases, the peak values of the humps increase, whereas the corresponding strain values decrease (cyan arrow in Fig. 4b). The strain hardening rate recovery is rapidly induced, but saturates early with increasing aging time. To understand this strain hardening recovery in terms of dislocation dynamics, we examined dislocation motions in the precipitationhardened alloys by in situ tensile TEM experiments focusing on the interactions between the gliding dislocations and precipitates.

In situ TEM results. Figure 5 shows the typical consecutive motion of the dislocation glide in the $3 \mathrm{~h}$-aged alloy. For a clearer visualization of the dislocation behavior, see Supplementary Movie 1. The sample geometry during the acquisition is provided in the form of Thompson's tetrahedron (Fig. 5h), visualizing the $\{111\}$ slip planes of FCC structure. The carbides exhibited a mottled feature on the matrix because the size of the $\kappa$-carbides was relatively small and the viewing direction was not parallel to the $<001>$ direction. During deformation, pairs of dislocations with the Burgers vector (b) of 1/2[110] continuously glided on a $\{111\}$ slip plane of the austenite matrix by shearing the $\kappa$-carbides precipitates. According to the $\boldsymbol{g} \cdot \boldsymbol{b}$ invisible criteria, the gliding dislocations were verified as mixed-type dislocations. The continuous flow of the planar gliding dislocations was comparable 


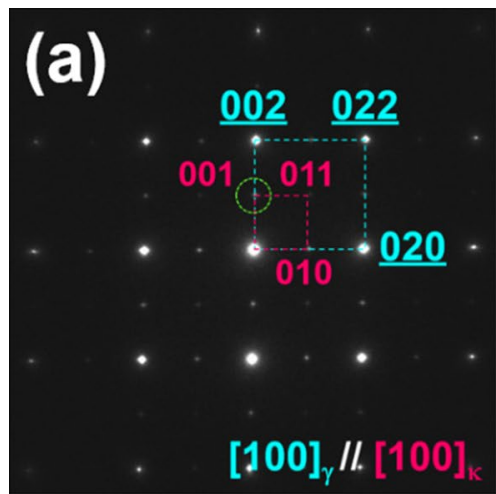

(b)
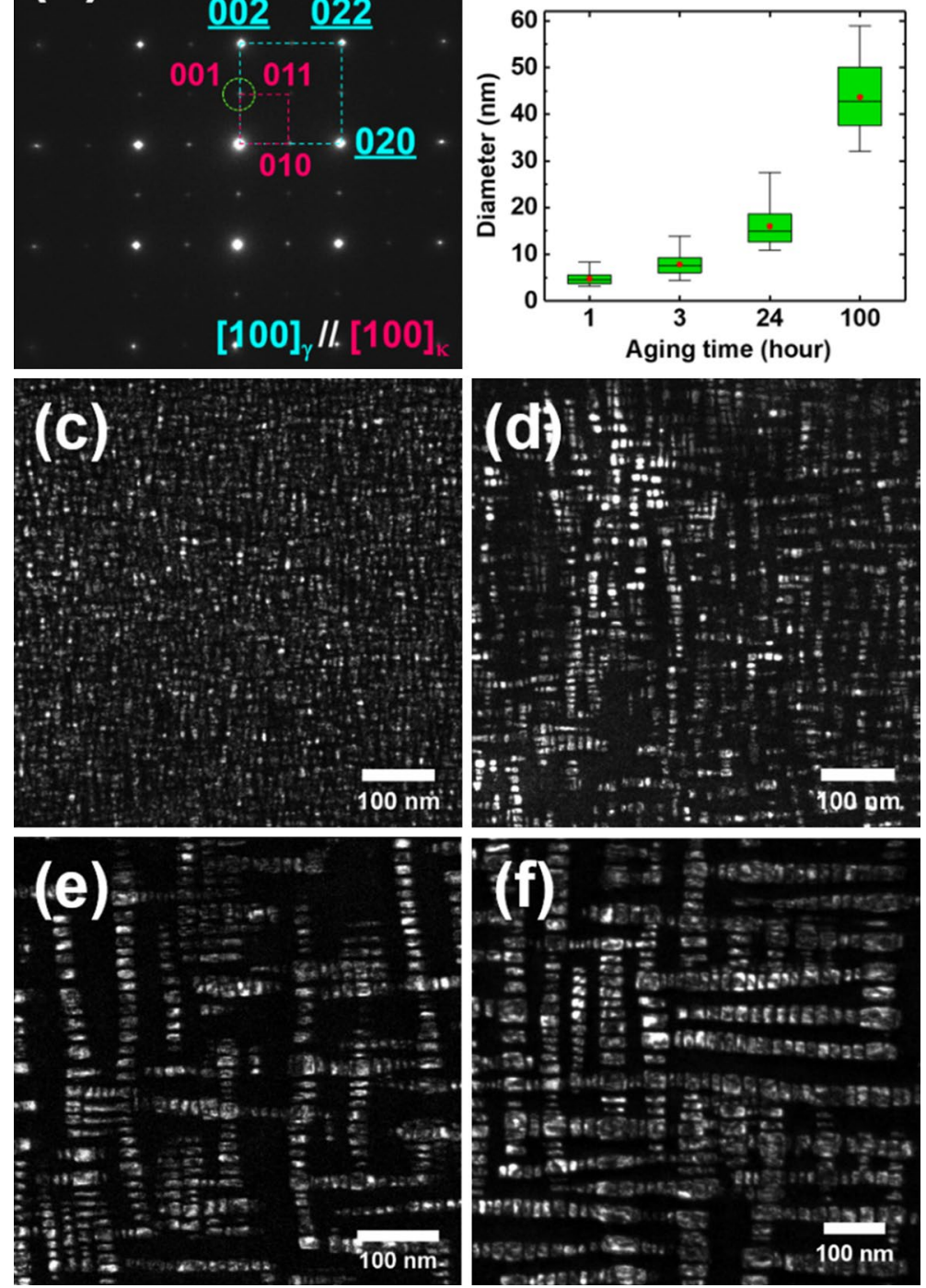

Figure 1. (a) Selected area diffraction pattern (SADP) of the aged Fe-Mn-Al-C alloy. (b) Size measurements of the $\kappa$-carbide with aging time. (c-f) Dark-field (DF) TEM images of 1,3, 24, and 100 h-aged alloys, respectively.

to that found during the deformation of an AS alloy ${ }^{41}$. However, the frequent impingement of the dislocation line (red arrows, Fig. 5) indicated that the gliding dislocations shear (cut) the carbides. The pairing of the gliding dislocations also confirmed that particle cutting is the dominant strengthening mechanism in the $3 \mathrm{~h}$-aged alloy, because the pairing removes the anti-phase boundary (APB) in the sheared $\kappa$-carbides ${ }^{14,15,18}$.

Figure 6 shows a representative dislocation-precipitate interaction during the deformation of the $24 \mathrm{~h}$-aged alloy (detailed information on the dislocation movement is provided in Supplementary Movie 2). Similar to the 3 h-aged alloy, mixed-type dislocations with a Burgers vector of $1 / 2[110]$ were gliding on a $\{111\}$ slip plane of the austenite matrix. However, in the $24 \mathrm{~h}$-aged alloy, the $\kappa$-carbide blocks were clearly distinguishable from the carbide-free wide matrix channels (Section "Deformation mechanism"). Deformation proceeded by the irregular flow of gliding dislocations overcoming the hindrance of the $\kappa$-carbide blocks, contrary to the steady motion observed in the $3 \mathrm{~h}$-annealed alloy. It is conceivable that the degree of strengthening by the precipitates increases as their size increases. The dislocations pass through the precipitate blocks without leaving any dislocation loop around the blocks, which implies that particle cutting is also the dominant deformation mechanism in the $24 \mathrm{~h}$-aged alloy.

Figure 7 shows the dislocation-precipitate interaction in the $100 \mathrm{~h}$-aged alloy (detailed information on the dislocation movement is provided in Supplementary Movie 3). In this case, the volume fraction of the $\kappa$-carbides is much higher than that of the $24 \mathrm{~h}$-aged alloy, and the dislocation movements are further disturbed when gliding on the slip plane. The particle cutting by gliding dislocations is also clearly captured in the visuals of the 100 h-aged alloy (Fig. 8 and Supplementary Movie 4-6), where the particle-dislocation interactions were acquired from viewing directions of $<110>,<100>$, and $<111>$. When viewed from the $<110>$ direction, it is particularly 

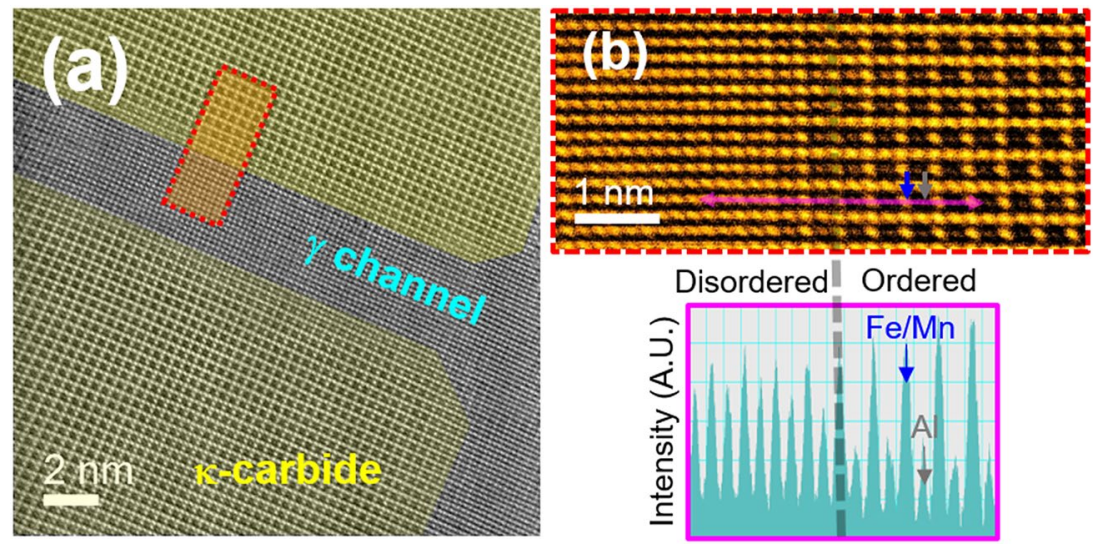

Figure 2. (a) High-angle annular dark-field (HAADF) STEM images of the 24 h-aged alloy acquired along the $<001>$ direction. (b-upper) Magnified HAADF-STEM image of the coherent interface between the precipitate and austenite matrix. (b-lower) Intensity profile measured from the magenta line on the (b-upper) image.

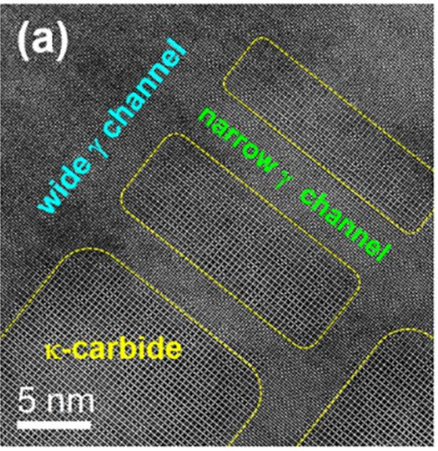

(e)
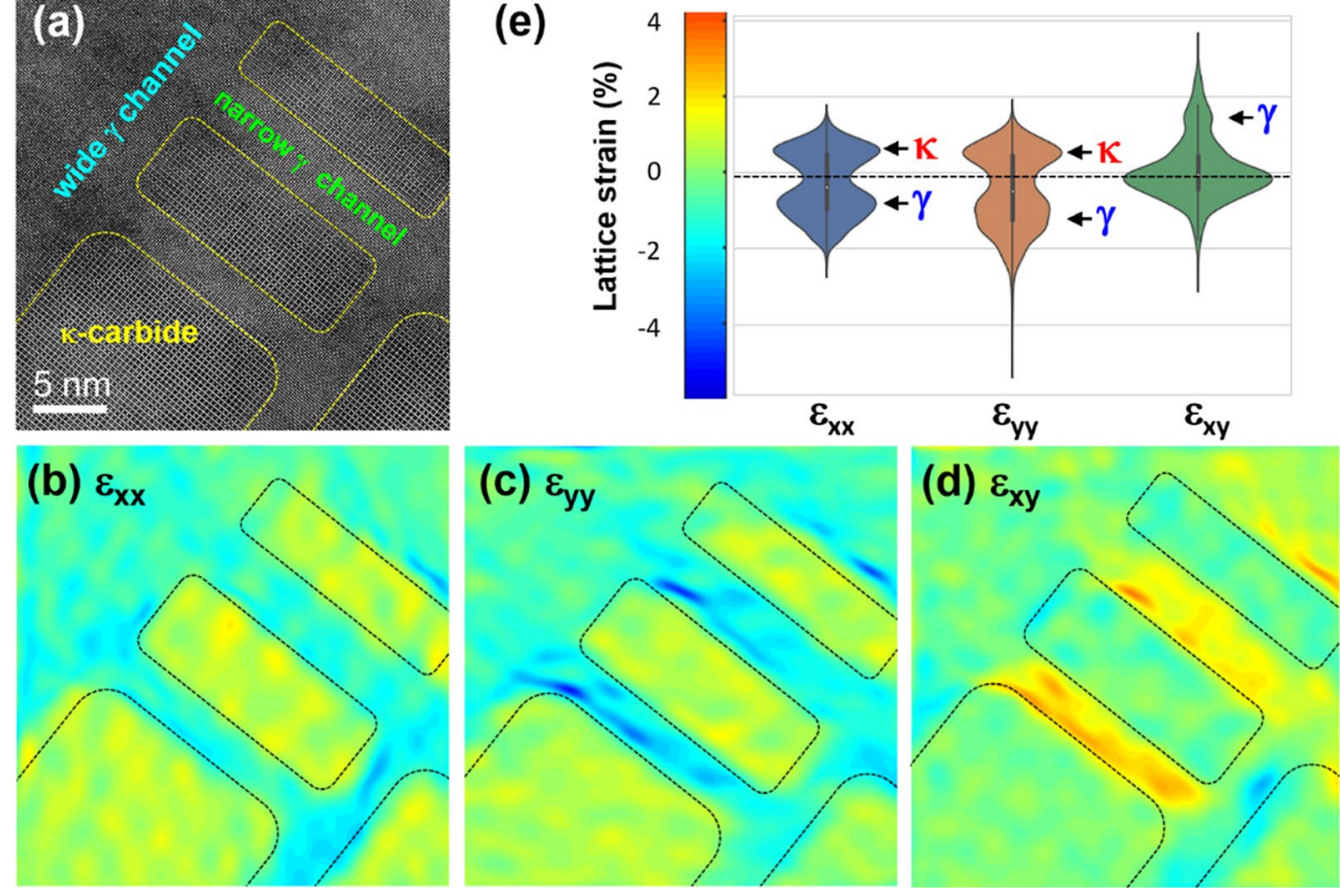

Figure 3. (a) HAADF-STEM image of the 24 h-aged Fe-Mn-Al-C alloy. (b-d) Geometric phase analysis (GPA) of (a). (e) Distribution of the lattice strains measured by GPA. The lattice strains were measured by using the $<100>$ reflections of the austenite matrix.

apparent that the precipitates were sheared by fine lines, implying that the dislocations shear the precipitates on particular glide planes (i.e., planar dislocation glide). As mentioned earlier, the shearing dislocations are readily bent by the pinning of the precipitates; thus, the dislocation line bending is more pronounced when the size of the precipitates is increased, as in the $100 \mathrm{~h}$-aged alloy. Therefore, in the $100 \mathrm{~h}$-aged alloy, some gliding dislocations are considerably bent up to $90^{\circ}$ (Fig. 9 and Supplementary Movie 7). Thus, the dislocation line vector of such a bent dislocation section is parallel to the dislocation gliding direction (i.e., Burgers vector, $\boldsymbol{b}$ ), implying that the bent section of the dislocations is transferred to the screw-type dislocation. It is known that screw-type dislocations in FCC materials easily transit their slip plane because their Burgers and line vectors are not confined in a unique plane $e^{20,24,42,43}$. Therefore, the screw-type dislocations originating from dislocation bending are easy to cross-slip onto other slip systems. Figure 10 shows such cross-slips of the screw dislocations in the $100 \mathrm{~h}$-aged alloy (from Supplementary Movie 8). In addition, it is noteworthy that the cross-slip consequently leads to the activation of the secondary slip system. 
(a)

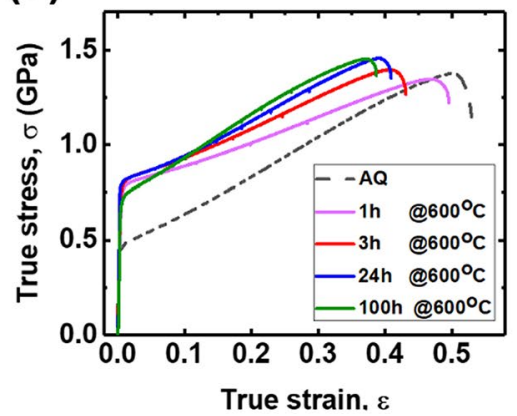

(b)

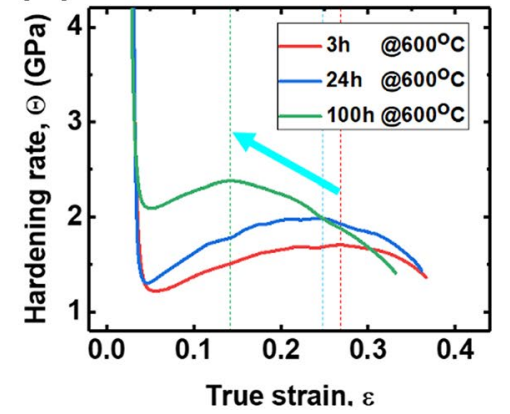

(c)

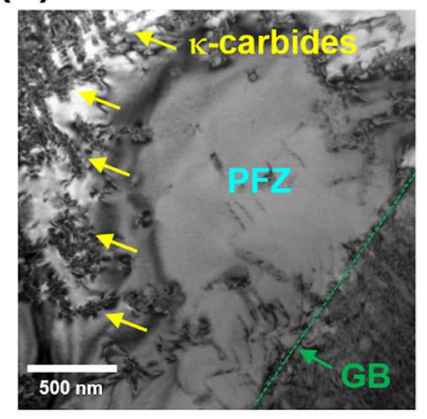

Figure 4. (a) True stress-strain curves of the aged alloys, and (b) their corresponding strain hardening rate curves measured at $293^{\circ} \mathrm{C}$. (c) BF-TEM image acquired in the vicinity of a grain boundary.
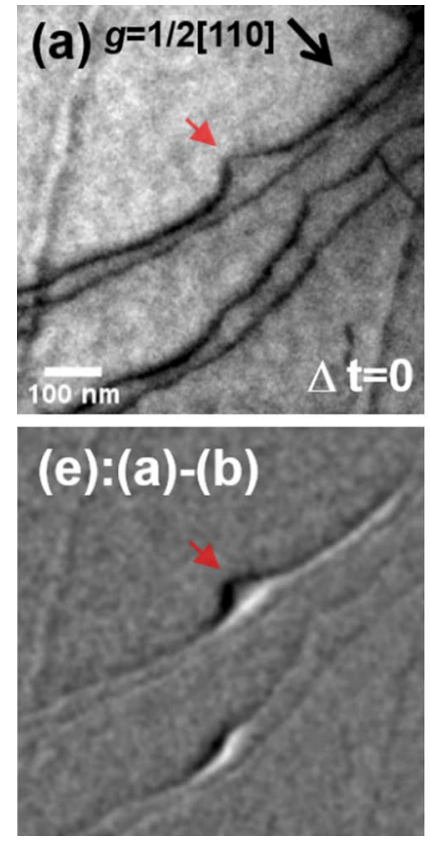
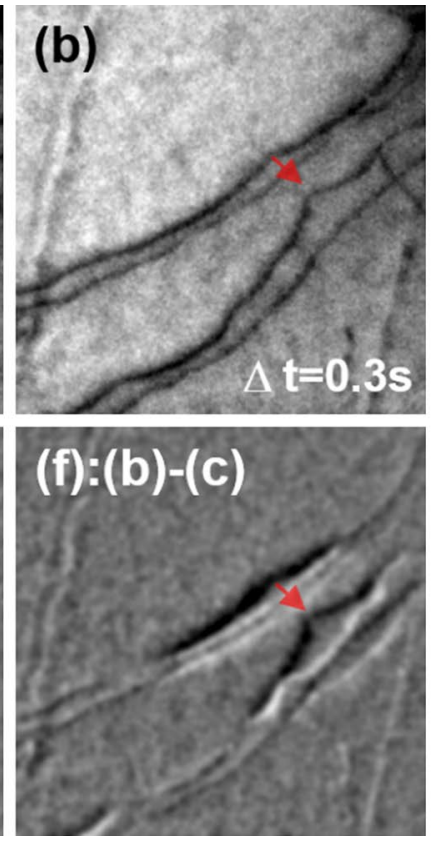
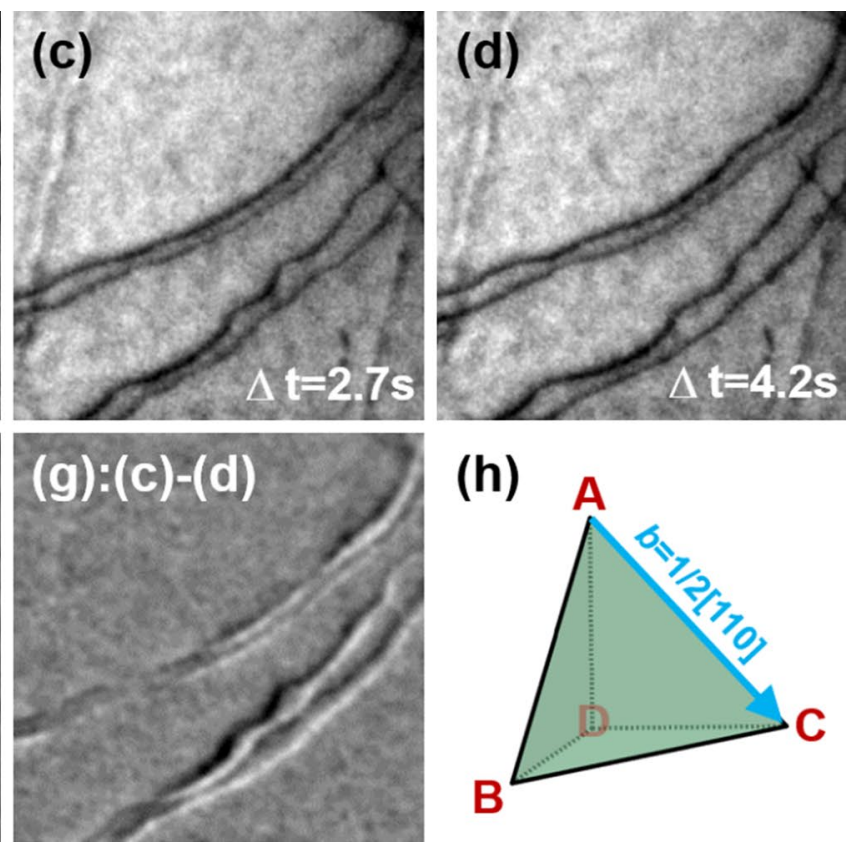

(h)

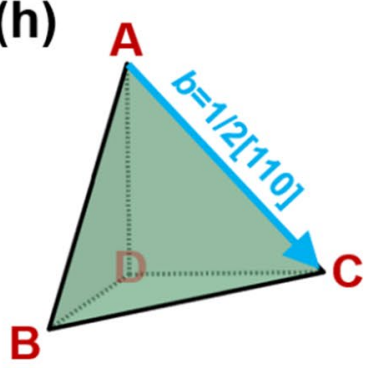

Figure 5. Dislocation gliding behavior in the $3 \mathrm{~h}$-aged alloy. (a-d) Snapshots (BF-TEM images) taken from Supplementary Movie 1. (e-g) Differences between snapshots in (a-d). (h) Thompson's tetrahedron showing the sample geometry.

\section{Discussion}

Deformation mechanism. The deformation mechanism in precipitation-hardened materials can be determined by comparing the YS increment (strengthening) using the Orowan looping $\left(\Delta \sigma_{\text {Orowan }}\right)$ and particle shearing $\left(\Delta \sigma_{\text {shearing }}\right)$ mechanisms, in which the deformation mechanism with a lower $\Delta \sigma$ dominates ${ }^{5,14,24,44}$.

Strengthening by the Orowan looping mechanism is expressed as $5^{5,14,24,44}$,

$$
\Delta \sigma_{\text {Orowan }}=M \frac{0.4 G b}{\pi \sqrt{1-v}} \frac{\ln (2 \overline{\mathrm{r}} / \mathrm{b})}{2 \bar{r}\left(\sqrt{\frac{\pi}{4 f}}-1\right)}
$$

where $M, G, b$, and $v$ are constants (mean orientation factor for FCC polycrystalline matrix, shear modulus of austenite matrix, the magnitude of the Burgers vector of $1 / 2[110]$, and Poisson's ratio, respectively). The equation consists of two variables, the radius $\left(r=\frac{\mathrm{r}}{\sqrt{2 / 3}}\right)$ and volume fraction $(f)$ of the precipitates, and $\Delta \sigma_{\text {Orowan }}$ increases as the $f$ of the precipitates increases. However, at a fixed $f, \Delta \sigma_{\text {Orowan }}$ is inversely proportional to the size of the precipitates. Hence, the Orowan looping mechanism is likely to operate in overaged precipitation-hardened alloys $22,24,43-45$.

Furthermore, there are three major factors that contribute to the strengthening caused by the particle shearing mechanism $\left(\Delta \sigma_{\text {shearing }}\right)$ : coherency strengthening $\left(\Delta \sigma_{\text {coherency }}\right)$, modulus mismatch strengthening $\left(\Delta \sigma_{\mathrm{ms}}\right)$, and order strengthening $\left(\Delta \sigma_{\text {order }}\right)^{5,14,24,44}$. Among them, coherency strengthening, the most determinant strengthening factor for particle shearing mechanism, is estimated as follows ${ }^{5,14,24,44}$ : 

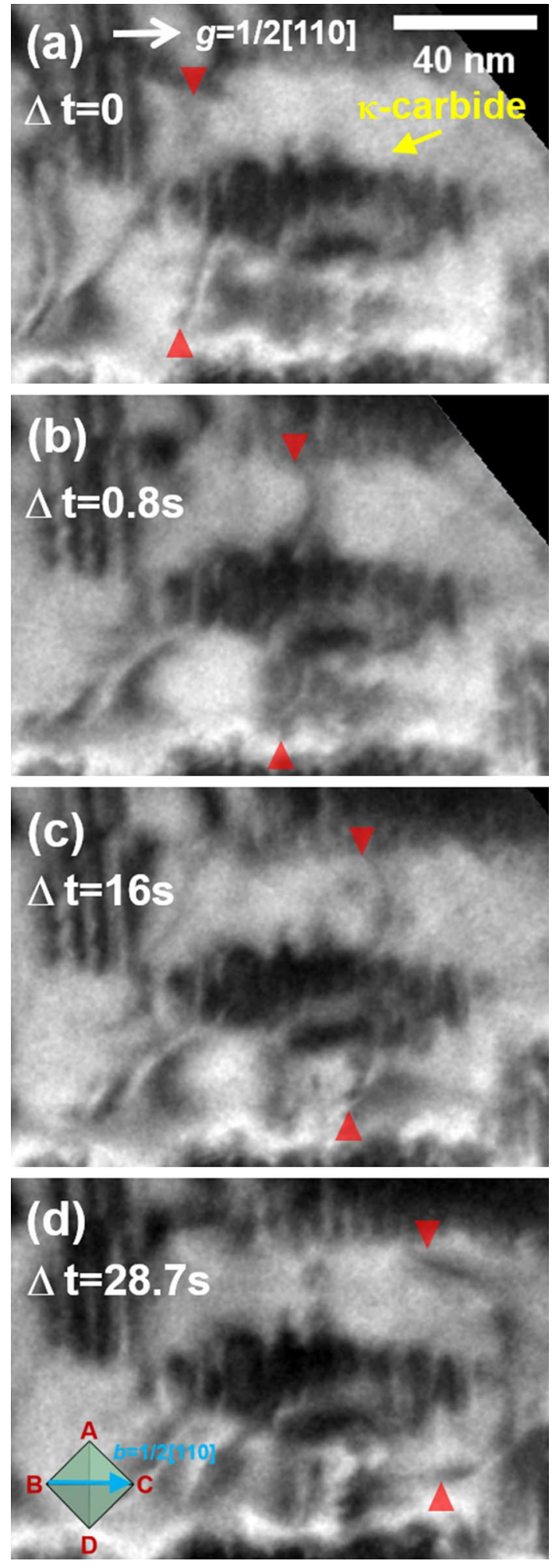

Figure 6. Dislocation-precipitate interaction during the deformation of the 24 h-aged alloy. (a-d) snapshots (BF-TEM images) taken from Supplementary Movie 2.

$$
\Delta \sigma_{\text {coherency }}=K M\left(G \varepsilon_{c}\right)^{\frac{3}{2}}\left(\frac{r f}{0.5 G b}\right)^{\frac{1}{2}}
$$



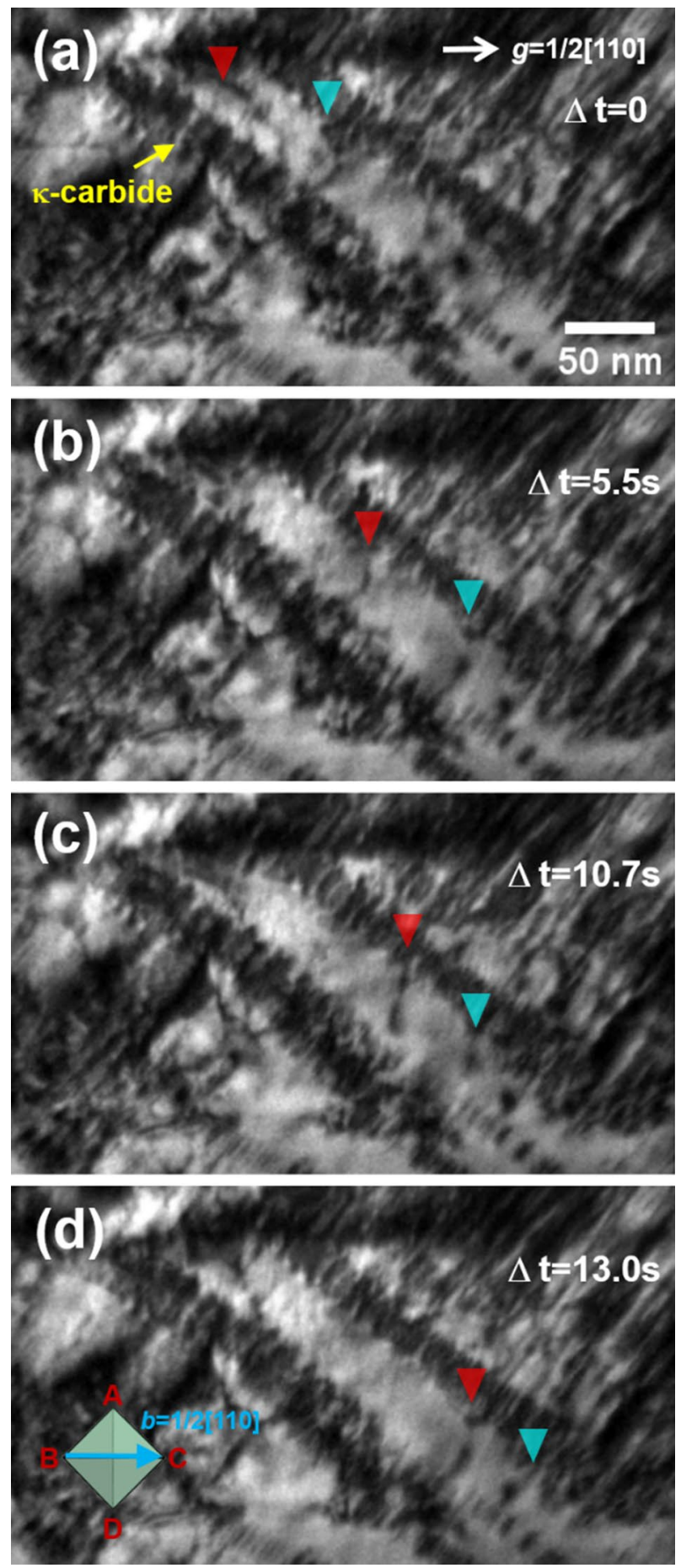

Figure 7. Dislocation-precipitates interaction in the $100 \mathrm{~h}$-aged alloy. (a-d) snapshots (BF-TEM images) taken from Supplementary Movie 3. Cyan and red triangle marks denote the location of gliding dislocations in each of the sequential snapshots, revealing the dislocation's gliding trajectory. Burgers vector of the gliding dislocations are indicated in the Thompson's tetrahedron (lower left in (d)).

where $K$ is a constant and $\varepsilon_{c}$ is the lattice misfit strain. Contrary to $\Delta \sigma_{\text {Orowan, }}$, the growth of the precipitates increases $\Delta \sigma_{\text {coherency, }}$ which inhibits the shearing of the precipitates by dislocations. On the contrary, in the case of aged $\mathrm{Fe}-\mathrm{Mn}$-Al-C alloys, the fully coherent $\kappa$-carbide precipitates effectively reduce the lattice misfit strain $\left(\varepsilon_{c} \approx 0\right)$, causing $\Delta \sigma_{\text {coherency }}$ to be negligible, and facilitating the shearing of the precipitates. As confirmed by GPA (Fig. 3), the precipitation of $\kappa$-carbides generates a negligible amount of lattice strains ( $<3 \%)$; consequently, particle shearing becomes the primary deformation mechanism even with relatively large-sized $\kappa$ carbide precipitates. Our in situ TEM results also confirmed that the deformation of the aged $\mathrm{Fe}-\mathrm{Mn}-\mathrm{Al}-\mathrm{C}$ alloys occurs via particle 

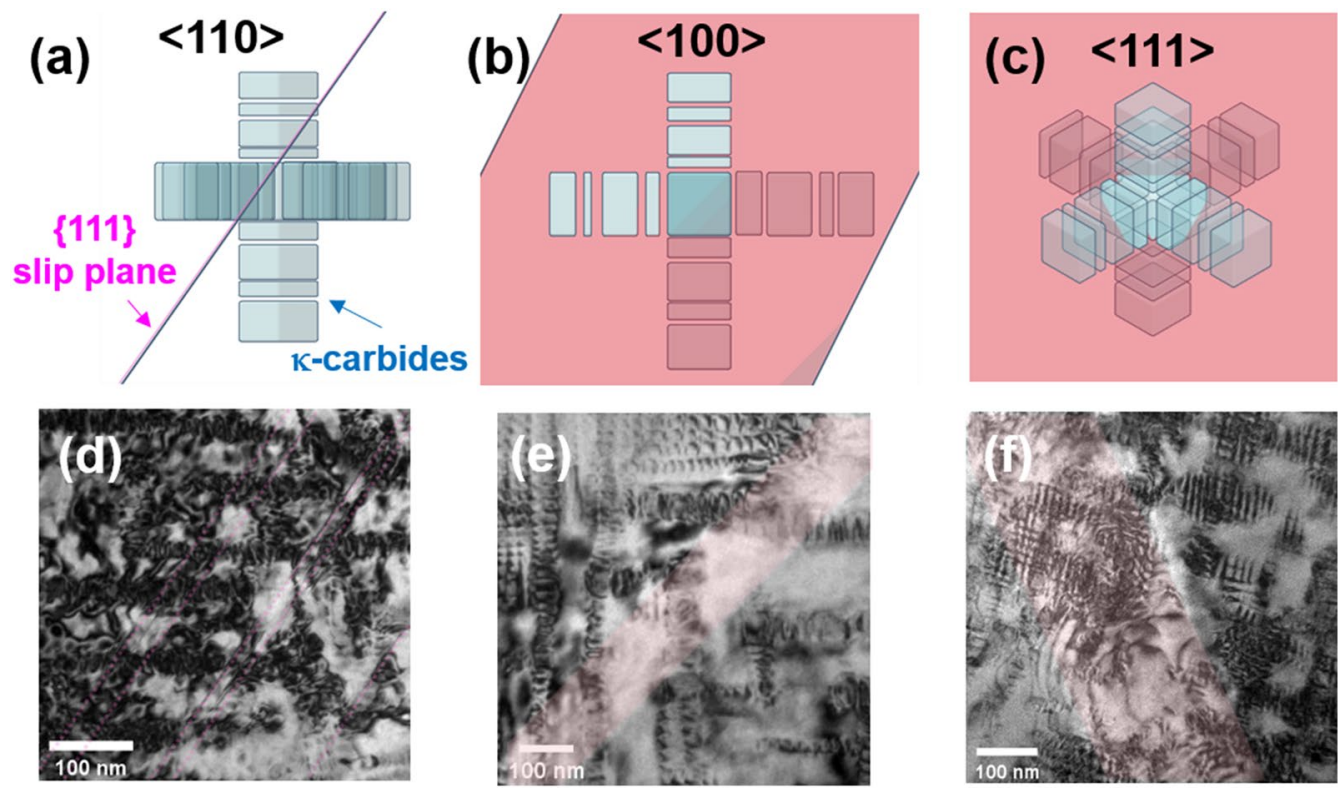

Figure 8. Precipitate-dislocation interactions observed along the $\langle 110\rangle,\langle 100\rangle$, and $<111\rangle$ directions. (a-c) Schematic illustrations of the $\kappa$-carbides blocks along with a $\{111\}$ slip plane. (d-f) Bright-field (BF) TEM images of the $100 \mathrm{~h}$-aged alloys from the viewing directions of $\langle 110\rangle,<100\rangle$, and $<111>$. Gliding plane of dislocations in the FCC structure are visualized by shaded magenta area.

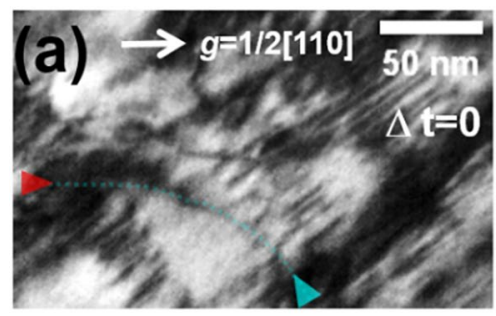

\section{(c)}
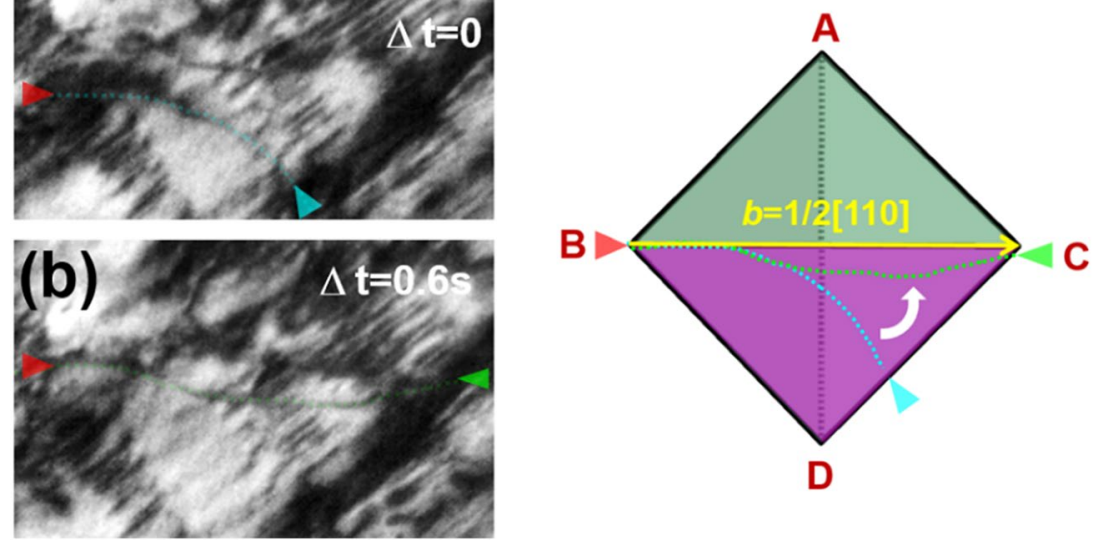

Figure 9. Bending of the dislocation by the precipitate pinning. (a,b) Snapshots (BF-TEM images) taken from Supplementary Movie 7. In the $100 \mathrm{~h}$-aged alloy, (a) some gliding dislocations are (b) considerably bent up to $90^{\circ}$. The dislocation bending is illustrated in (c). The dislocation line vector of such a bent dislocation section is parallel to the dislocation gliding direction (i.e., Burgers vector, $\mathbf{b}$ ).

shearing. Detailed calculations and microscopic investigations in previous studies ${ }^{16,18}$ suggest that the particle shearing mechanism is energetically favorable when the precipitate size is below a critical value.

When particle shearing occurs, dislocation shearing reduces the effective size of the precipitates as follows ${ }^{16,26,30,43}$,

$$
r_{e f f}=\bar{r}-\frac{n b}{2}
$$

where $\mathrm{n}$ is the number of shearing dislocations. In other words, each shearing reduces the effective radius of the precipitates, which helps the following dislocations shear the precipitates on the same slip plane (known as "glide plane softening") $)^{2,3,6,7,9,11,14-16,18}$. Therefore, the particle shearing in the aged Fe-Mn-Al-C alloys leads to the planar dislocation glide. In summary, it can be concluded that the high degree of lattice coherency between 

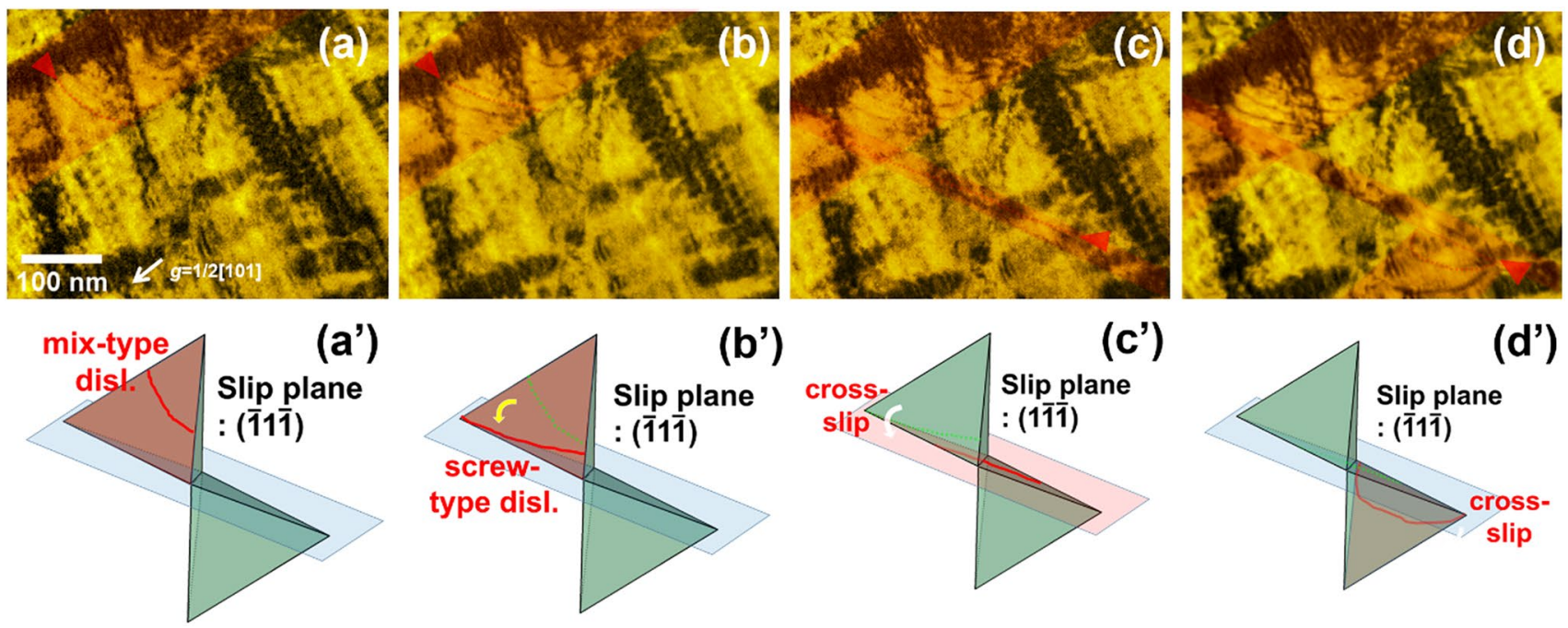

Figure 10. Cross-slips of the screw dislocations in the $100 \mathrm{~h}$-aged alloy. (a-d) Snapshots (BF-TEM images) taken from Supplementary Movie 8, and (a'-d') corresponding illustrations.

the $\kappa$-carbides and austenite matrix enables the dislocations to shear the precipitates, reducing the resistivity of the precipitates toward the dislocation glide, and thereby causing a pronounced planar dislocation glide.

Strain hardening behavior. Recently, the SASH model ${ }^{26}$ was proposed to quantitatively interpret the strain hardening recovery. It comprehensively interprets the strain hardening recovery behavior of twinninginduced plasticity (TWIP) steels and precipitation-hardened Ni alloys by considering the three dominating factors: forest dislocation density, orientation factor $\left(\mathrm{M}^{\prime \prime}\right)$, and dislocation mean free path (mobile dislocation density). The governing ordinary differential equations can be written as,

$$
\begin{aligned}
\frac{d \rho_{f}}{d \epsilon_{p}} & =M^{\prime \prime}\left(\frac{1}{b L}-K_{2} \rho_{f}\right) \\
\frac{d M^{\prime \prime}}{d \epsilon_{p}} & =K_{M}\left(M_{s}^{\prime \prime}-M^{\prime \prime}\right) \\
\frac{d L}{d \epsilon_{p}} & =-K_{L}\left(L-L_{s}\right)
\end{aligned}
$$

$\rho_{\mathrm{f}}$ is the forest dislocation density, $\varepsilon_{\mathrm{p}}$ is a plastic strain, and $\mathrm{M}_{\mathrm{S}}$ " and $\mathrm{L}_{\mathrm{S}}$ are the saturation value of the orientation factor (M") and the dislocation mean free path $(L)$, respectively. $\mathrm{K}_{\mathrm{M}}$ is related to the orientation factor, which is no longer constant and varies with deformation. The variable $K_{2}$ is related to dislocation removal by dynamic recovery. $\mathrm{K}_{\mathrm{L}}$ defines the rate at which the dislocation mean free path approaches its saturation value $\left(\mathrm{L}_{\mathrm{S}}\right)$. The strain hardening rate curves of the precipitation-hardened alloys were fitted using the SASH model (Fig. 11, Table 1 (fitting parameters)). It can be seen that the most remarkable feature is the change in $\mathrm{K}_{\mathrm{L}}$ values with increasing aging time. The $\mathrm{K}_{\mathrm{L}}$ values of the $3 \mathrm{~h}$ and $24 \mathrm{~h}$-aged alloys are comparable, but that of the $100 \mathrm{~h}$-aged alloy is quite large, implying that the dislocation mean free path in the $100 \mathrm{~h}$ alloy is more rapidly saturated than in the $3 \mathrm{~h}$ or $24 \mathrm{~h}$-aged alloys. This trend in the mechanical property corresponds to the dislocation behaviors observed in the in situ experiment. As mentioned earlier, a frequent cross-slip of gliding dislocations was noted during the deformation of the $100 \mathrm{~h}$-aged alloys. The bigger and harder $\kappa$-carbides act as effective barriers against dislocation motion and subsequently bend the dislocations by making the line vector $(\boldsymbol{u})$ parallel to the Burgers vector $(\boldsymbol{b})$; the type of dislocations is changed from edge to screw. The screw dislocations are easy to cross-slip, promoting early activation of the secondary slip system. Accordingly, the simultaneous activation of multiple slip systems leads to additional barriers to the dislocation glide, and consequently, an abrupt decline in the dislocation mean free path.

Figure 12 shows the simulated strain hardening curves according to the SASH model (Fig. 12a), and their corresponding dislocation mean free path graphs (Fig. 12b). To reveal the relationships between the strain hardening recovery and dislocation mean free path, fitting parameters for the $100 \mathrm{~h}$-aged alloy from Table 1 were used to simulate the strain hardening rate curves. The strain hardening recovery activated when the dislocation mean free path was larger than a critical value $(\sim 1.7 \mu \mathrm{m})$. It is reasonable to deduce that the early disappearance of the strain hardening recovery in the $100 \mathrm{~h}$-aged alloy is due to the rapid decrease in the dislocation mean free path. Hence, preserving the dislocation mean free path by suppressing the cross-slip or promoting the planar glide might be essential to induce strain hardening recovery. 


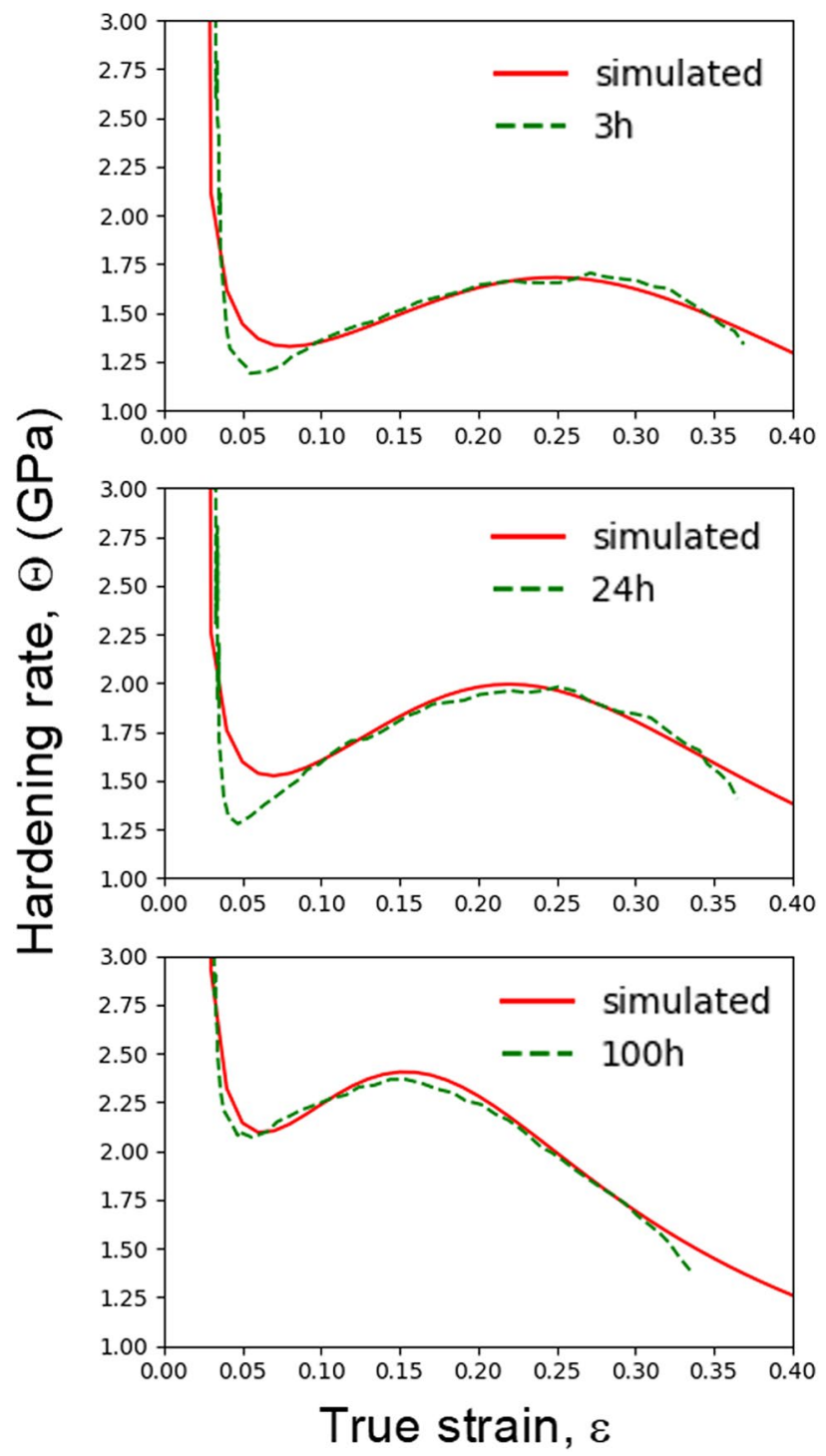

Figure 11. Strain hardening rate curves of the aged alloys (green dotted lines), and their corresponding simulated strain hardening fitted using the SASH model (red lines).

\begin{tabular}{|l|l|l|l|l|}
\hline Alloy & $\mathbf{3} \mathbf{h}$ & $\mathbf{2 4} \mathbf{h}$ & $\mathbf{1 0 0} \mathbf{h}$ & Description \\
\hline$\rho_{0}$ & $1^{\star} 10^{11}$ & $1^{\star} 10^{11}$ & $1^{\star} 10^{11}$ & Initial value of dislocation density ${ }^{26}$ \\
\hline $\mathrm{M}_{0}$ & 2.2 & 2.2 & 2.2 & Initial value of $\mathrm{M}^{26}$ \\
\hline $\mathrm{M}_{\mathrm{S}}$ & 3.0 & 3.0 & 3.0 & Saturated value of $\mathrm{M}^{26}$ \\
\hline $\mathrm{L}_{0}(\mathrm{~m})$ & $3^{\star} 10^{-6}$ & $3^{\star} 10^{6}$ & $3^{\star} 10^{6}$ & Initial value of $\mathrm{L}$ \\
\hline $\mathrm{L}_{\mathrm{S}}(\mathrm{m})$ & $1^{\star} 10^{7}$ & $1^{\star} 10^{7}$ & $1^{\star} 10^{7}$ & Saturated value of $\mathrm{L}$ \\
\hline $\mathrm{K}_{\mathrm{M}}$ & 10 & 10 & 10 & Rate of $\mathrm{M}$ approaching $\mathrm{M}_{\mathrm{S}}$ \\
\hline $\mathrm{K}_{\mathrm{L}}$ & 13 & 15 & 20 & Rate of L approaching $\mathrm{L}_{\mathrm{S}}$ \\
\hline $\mathrm{K}_{2}$ & 0.2 & 0.3 & 0.5 & Rate of dislocation recovery \\
\hline
\end{tabular}

Table 1. Parameters for fitting the strain hardening rate curves of the precipitation-hardened alloys to the SASH model. 
(a)

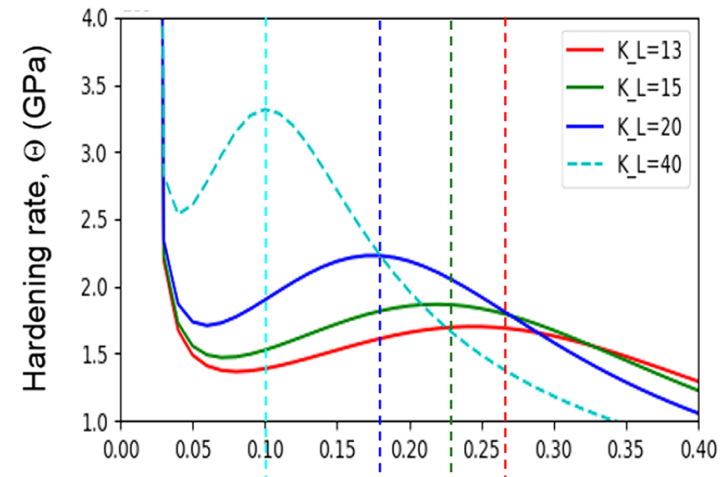

(b)

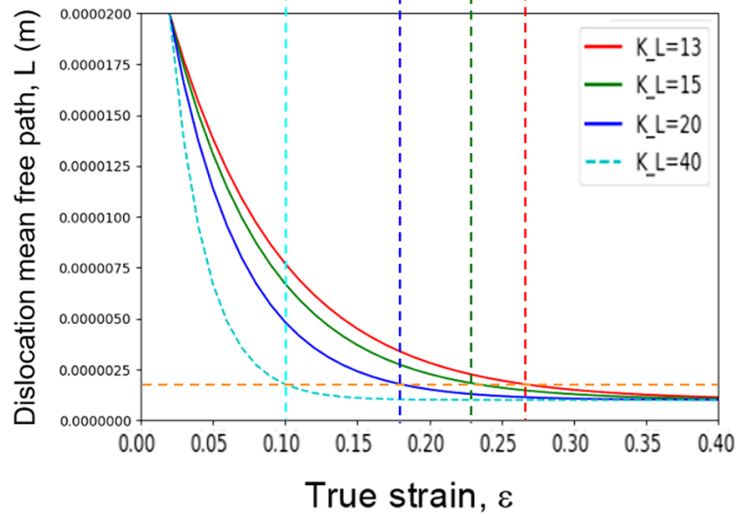

Figure 12. Strain hardening curves simulated by the SASH model (upper), and their corresponding dislocation mean free path graph (lower).

Assuming that the strain hardening rate recovery of the precipitation-hardened $\mathrm{Fe}-\mathrm{Mn}$-Al-C alloys can be enabled by the planar slip deformation, the strain hardening recovery behavior in the TWIP and phase transformation-induced plasticity (TRIP) steels also can be explained by their characteristic planar slip behaviors. Due to their low stacking fault energy, the dislocation behaviors in TWIP and TRIP steels are characterized by the pronounced planar glide of Shockley partial dislocations ${ }^{46-51}$, generating abundant stacking faults, which are the building blocks for twin and epsilon martensite ${ }^{46-51}$. Therefore, in TWIP and TRIP steels, cross-slip and the simultaneous activation of multiple slip systems are inhibited by the planar glide of the Shockley partial, allowing the recovery of the strain hardening rate.

Thus, if we could design a microstructure where the dislocations glide in a planar manner, and dislocation cross-slip and the simultaneous onset of multiple slip systems is suppressed with the ongoing plastic deformation, the strain hardening recovery could be utilized optimally to obtain enhanced mechanical properties.

\section{Conclusions}

In the present study, we investigated the effect of $\kappa$-carbide precipitates on the strain hardening behavior of aged $\mathrm{Fe}-\mathrm{Mn}-\mathrm{Al}-\mathrm{C}$ alloys from a microscopic point of view. Via comprehensive TEM analyses, including HAADFSTEM and in situ straining TEM, the following conclusions were drawn:

- Rectangular parallelepiped-shaped $\kappa$-carbides with coherent $\{001\} \kappa$ - ${ }_{\text {carbide }} / /\{001\}_{\text {austenite }}$ habit planes were precipitated after the isothermal aging of Fe-Mn-Al-C alloys at $600{ }^{\circ} \mathrm{C}$ for various times. The sizes of the precipitates increased with the aging time, but the lattice coherency between the precipitates and matrix was preserved even after $100 \mathrm{~h}$ of aging.

- By the precipitation of $\kappa$-carbides, the YS and flow stress were considerably increased compared to those of the AS alloy. Recovery of the strain hardening rate occurred in the aged Fe-Mn-Al-C alloys. As the aging time increased, the strain hardening recovery saturated faster.

- Results of the in situ tensile TEM experiments confirmed that the particle shearing mechanism occurs in the aged $\mathrm{Fe}-\mathrm{Mn}-\mathrm{Al}-\mathrm{C}$ alloys. The origin behind this mechanism was deduced to be the considerable reduction in $\Delta \sigma_{\text {shearing }}$ by the high degree of lattice coherency between the $\kappa$-carbides and austenite matrix.

- During deformation of the $100 \mathrm{~h}$-aged alloy, some gliding dislocations were strongly pinned by the large $\kappa$-carbide blocks, and consequently, severely bent. The bent dislocations were easy to cross-slip into other slip planes, promoting the activation of multiple slip systems. The abrupt decline in the dislocation mean free path was attributed to the activation of multiple slip systems, leading to the saturation of the strain hardening rate recovery at lower strain levels. 
- It can be assumed that the strain hardening recovery is closely related to the pronounced planar dislocation glide. Accordingly, if a microstructure where the dislocations glide in a planar manner is designed, the strain hardening recovery can be utilized to enhance the mechanical properties in lightweight steels.

\section{Methods}

Methods for sample preparation and microstructure analysis are adopted from the author's previous study ${ }^{41}$. The chemical composition of the investigated alloy was Fe-32Mn-8.9Al-0.78C (wt. \%). The alloy was melted in an induction furnace and cast into a $60 \mathrm{~kg}$ ingot $(180 \mathrm{~mm}$ dia. $\times 250 \mathrm{~mm}$ height $)$ under vacuum. The ingot was homogenized for $5 \mathrm{~h}$ at $1220^{\circ} \mathrm{C}$ and forged into a block $(70 \times 120 \times 750 \mathrm{~mm})$; subsequently, plate-shaped samples $(70 \times 120 \times 20 \mathrm{~mm})$ were cut from the block, followed by solution treatment at $1050^{\circ} \mathrm{C}$ for $5 \mathrm{~h}$ and subsequent water quenching. The as-solution-treated samples were isothermally annealed at $600{ }^{\circ} \mathrm{C}$ for various times $(1,3$, 24 , and $100 \mathrm{~h}$ ) and water-quenched to promote the formation of $\kappa$-carbides. Cylindrical tensile samples were obtained from the plate sample with a gage dimension of $6.25 \mathrm{~mm}$ diameter and $25 \mathrm{~mm}$ length. Tensile tests were carried out at $293{ }^{\circ} \mathrm{C}$ with a strain rate of 0.008 /s using a tensile test machine (INSTRON 5982, Canton, MA). The precipitation state of the annealed samples was investigated using TEM. For a conventional post-mortem TEM analysis, disks with a diameter of $3 \mathrm{~mm}$ were mechanically polished to approximately $100 \mu \mathrm{m}$ thickness and electrochemically etched by an electrolytic twin-jet polishing machine (TenuPol-5, Struers). The electrochemical etching was conducted at $10 \mathrm{~V}$ and $70 \mathrm{~mA}$ with a mixed solution of $10 \%$ perchloric acid and $90 \%$ methanol at $-20^{\circ} \mathrm{C}$. Samples for the in situ tensile TEM experiments were prepared to specific dimensions $(3 \mathrm{~mm} \times 12 \mathrm{~mm})$ by punching the polished foil using a custom-made foil puncher. The in situ TEM samples were also finally etched using the aforementioned etching condition. The TEM (JEM-2100F, JEOL Ltd, Japan.) equipment was operated at an acceleration voltage of $200 \mathrm{kV}$, and an in situ straining TEM holder (straining in situ holder- model 654, Gatan, Inc, USA.) was used for the in situ experiments. Average size of the carbide is calculated by using the particle analyzing algorithm in ImageJ software. To measure the average size of the $\kappa$-carbides, we used 10 DFTEM images from each sample.

Received: 12 April 2021; Accepted: 10 June 2021

Published online: 14 July 2021

\section{References}

1. Frommeyer, G. \& Brüx, U. Microstructures and mechanical properties of high-strength Fe-Mn-Al-C light-weight TRIPLEX steels. Steel Res. Int. 77, 627-633. https://doi.org/10.1002/srin.200606440 (2006).

2. Kim, H., Suh, D. W. \& Kim, N. J. Fe-Al-Mn-C lightweight structural alloys: A review on the microstructures and mechanical properties. Sci. Technol. Adv. Mater. 14, 014205. https://doi.org/10.1088/1468-6996/14/1/014205 (2013).

3. Raabe, D. et al. Alloy design, combinatorial synthesis, and microstructure-property relations for low-density $\mathrm{Fe}-\mathrm{Mn}$-Al-C austenitic steels. JOM 66, 1845-1856. https://doi.org/10.1007/s11837-014-1032-x (2014).

4. Chen, S., Rana, R., Haldar, A. \& Ray, R. K. Current state of Fe-Mn-Al-C low density steels. Prog. Mater. Sci. 89, 345-391. https:// doi.org/10.1016/j.pmatsci.2017.05.002 (2017).

5. Choo, W. K., Kim, J. H. \& Yoon, J. C. Microstructural change in austenitic Fe-30.0wt\%Mn-7.8wt\%Al-1.3wt\%C initiated by spinodal decomposition and its influence on mechanical properties. Acta Mater. 45, 4877-4885. https://doi.org/10.1016/S1359-6454(97) 00201-2 (1997).

6. Yoo, J. D. \& Park, K.-T. Microband-induced plasticity in a high Mn-Al-C light steel. Mater. Sci. Eng., A 496, 417-424. https://doi. org/10.1016/j.msea.2008.05.042 (2008).

7. Yoo, J. D., Hwang, S. W. \& Park, K. T. Origin of extended tensile ductility of a Fe-28Mn-10Al-1C steel. Metall. and Mater. Trans. A. 40, 1520-1523. https://doi.org/10.1007/s11661-009-9862-9 (2009).

8. Choi, K. et al. Effect of aging on the microstructure and deformation behavior of austenite base lightweight Fe-2.8Mn-9Al-08C steel. Script. Mater. 63, 1028-1031. https://doi.org/10.1016/j.scriptamat.2010.07.036 (2010).

9. Park, K.-T. et al. Stacking fault energy and plastic deformation of fully austenitic high manganese steels: Effect of Al addition. Mater. Sci. Eng., A 527, 3651-3661. https://doi.org/10.1016/j.msea.2010.02.058 (2010).

10. Gutierrez-Urrutia, I. \& Raabe, D. Multistage strain hardening through dislocation substructure and twinning in a high strength and ductile weight-reduced Fe-Mn-Al-C steel. Acta Mater. 60, 5791-5802. https://doi.org/10.1016/j.actamat.2012.07.018 (2012).

11. Park, K.-T. Tensile deformation of low-density Fe-Mn-Al-C austenitic steels at ambient temperature. Scripta Mater. 68, 375-379. https://doi.org/10.1016/j.scriptamat.2012.09.031 (2013).

12. Cheng, W.-C., Cheng, C.-Y., Hsu, C.-W. \& Laughlin, D. E. Phase transformation of the L1 2 phase to kappa-carbide after spinodal decomposition and ordering in an Fe-C-Mn-Al austenitic steel. Mater. Sci. Eng., A 642, 128-135. https://doi.org/10.1016/j.msea. 2015.06.096 (2015).

13. Wu, Z. Q., Ding, H., An, X. H., Han, D. \& Liao, X. Z. Influence of Al content on the strain-hardening behavior of aged low density Fe-Mn-Al-C steels with high Al content. Mater. Sci. Eng., A 639, 187-191. https://doi.org/10.1016/j.msea.2015.05.002 (2015).

14. Kim, C. W. et al. Atomistic study of nano-sized $\kappa$-carbide formation and its interaction with dislocations in a cast Si added FeMnAlC lightweight steel. Mater. Sci. Eng., A 673, 108-113. https://doi.org/10.1016/j.msea.2016.07.029 (2016).

15. Welsch, E. et al. Strain hardening by dynamic slip band refinement in a high-Mn lightweight steel. Acta Mater. 116, $188-199$. https://doi.org/10.1016/j.actamat.2016.06.037 (2016).

16. Yao, M. J. et al. Combined atom probe tomography and density functional theory investigation of the $\mathrm{Al}$ off-stoichiometry of $\kappa$-carbides in an austenitic Fe-Mn-Al-C low density steel. Acta Mater. 106, 229-238. https://doi.org/10.1016/j.actamat.2016.01. 007 (2016).

17. Haase, C. et al. On the deformation behavior of $\kappa$-carbide-free and $\kappa$-carbide-containing high-Mn light-weight steel. Acta Mater. 122, 332-343. https://doi.org/10.1016/j.actamat.2016.10.006 (2017).

18. Yao, M. J. et al. Strengthening and strain hardening mechanisms in a precipitation-hardened high-Mn lightweight steel. Acta Mater. 140, 258-273. https://doi.org/10.1016/j.actamat.2017.08.049 (2017).

19. Seeger, A., Diehl, J., Mader, S. \& Rebstock, H. Work-hardening and work-softening of face-centred cubic metal crystals. Philos. Mag. 2, 323-350. https://doi.org/10.1080/14786435708243823 (1957).

20. Mader, S., Seeger, A. \& Thieringer, H. M. Work hardening and dislocation arrangement of fcc single crystals. II. Electron microscope transmission studies of Ni-Co single crystals and relation to work-hardening theory. J. Appl. Phys. 34, 3376-3386. https:// doi.org/10.1063/1.1729195 (1963). 
21. Nabarro, F. R. N., Basinski, Z. S. \& Holt, D. B. The plasticity of pure single crystals. Adv. Phys. 13, 193-323. https://doi.org/10.1080/ 00018736400101031 (1964).

22. Rollett, A. D. \& Kocks, U. F. A Review of the Stages of Work Hardening. Solid State Phenom. 35-36, 1-18 (1993).

23. Canadinc, D., Sehitoglu, H., Maier, H. J. \& Chumlyakov, Y. I. Strain hardening behavior of aluminum alloyed Hadfield steel single crystals. Acta Mater. 53, 1831-1842. https://doi.org/10.1016/j.actamat.2004.12.033 (2005).

24. Meyers, M. A. \& Chawla, K. K. Mechanical Behavior of Materials 2nd edn. (Cambridge University Press, 2008).

25. Yang, C. L., Zhang, Z. J., Cai, T., Zhang, P. \& Zhang, Z. F. Recovery of strain-hardening rate in Ni-Si alloys. Sci. Rep. 5, 15532. https://doi.org/10.1038/srep15532 (2015).

26. Mishra, S., Yadava, M., Kulkarni, K. N. \& Gurao, N. P. A new phenomenological approach for modeling strain hardening behavior of face centered cubic materials. Acta Mater. 178, 99-113. https://doi.org/10.1016/j.actamat.2019.08.002 (2019).

27. Moon, J. et al. Atomistic investigations of $\mathrm{K}$-carbide precipitation in austenitic Fe-Mn-Al-C lightweight steels and the effect of Mo addition. Scripta Mater. 127, 97-101. https://doi.org/10.1016/j.scriptamat.2016.08.036 (2017).

28. Sato, K., Tagawa, K. \& Inoue, Y. Spinodal decomposition and mechanical properties of an austenitic Fe-30wt\%Mn-9wt\%Al-09wt\%C alloy. Mater. Sci. Eng. A 111, 45-50. https://doi.org/10.1016/0921-5093(89)90196-2 (1989).

29. Yang, K. H. \& Choo, W. K. Evidence of carbon ordering and morphology change in a cubic carbide phase. Philos. Mag. Lett. 62, 221-226. https://doi.org/10.1080/09500839008215062 (1990).

30. Ru, Y. et al. Dislocation network with pair-coupling structure in $111 \gamma / \gamma^{\prime}$ interface of Ni-based single crystal superalloy. Sci. Rep. 6, 29941. https://doi.org/10.1038/srep29941 (2016).

31. Jouiad, M., Clément, N. \& Coujou, A. Friction stresses in the $\gamma$ phase of a nickel-based superalloy. Philos. Mag. A 77, 689-699. https://doi.org/10.1080/01418619808224077 (1998).

32. Jouiad, M., Pettinari, F., Clément, N. \& Coujou, A. Dynamic friction stresses in the $\gamma$ phase of a nickel-based superalloy. Philos. Mag. A 79, 2591-2602. https://doi.org/10.1080/01418619908212011 (1999).

33. Reed, R. C. The Superalloys: Fundamentals and Applications (Cambridge University Press, 2008).

34. Pennycook, S. J. in Advances in Imaging and Electron Physics Vol. 123 (eds Peter W. Hawkes, Pier Georgio Merli, Gianluca Calestani, \& Marco Vittori-Antisari) 173-206 (Elsevier, 2002).

35. Nellist, P. D. \& Pennycook, S. J. in Advances in Imaging and Electron Physics Vol. 113 (ed Peter W. Hawkes) 147-203 (Elsevier, 2000).

36. Pennycook, S. J. Z-contrast stem for materials science. Ultramicroscopy 30, 58-69. https://doi.org/10.1016/0304-3991(89)90173-3 (1989).

37. Klinger, M. \& Jäger, A. Crystallographic Tool Box (CrysTBox): automated tools for transmission electron microscopists and crystallographers. J. Appl. Crystallogr. 48, 2012-2018. https://doi.org/10.1107/s1600576715017252 (2015).

38. Hÿtch, M. J., Snoeck, E. \& Kilaas, R. Quantitative measurement of displacement and strain fields from HREM micrographs. Ultramicroscopy 74, 131-146. https://doi.org/10.1016/S0304-3991(98)00035-7 (1998).

39. Porter, D. A. \& Easterling, K. E. Phase Transformations in Metals and Alloys (Revised Reprint) (CRC Press, 2009).

40. Lütjering, G., Albrecht, J., Sauer, C. \& Krull, T. The influence of soft, precipitate-free zones at grain boundaries in Ti and $\mathrm{Al}$ alloys on their fatigue and fracture behavior. Mater. Sci. Eng., A 468-470, 201-209. https://doi.org/10.1016/j.msea.2006.07.168 (2007).

41. Kim, S.-D. et al. Direct observation of dislocation plasticity in high-Mn lightweight steel by in-situ TEM. Sci. Rep. 9, 15171. https:// doi.org/10.1038/s41598-019-51586-y (2019).

42. Gerold, V. \& Karnthaler, H. P. On the origin of planar slip in f.c.c. alloys. Acta Metall. 37, 2177-2183. https://doi.org/10.1016/ 0001-6160(89)90143-0 (1989).

43. Hull, D. \& Bacon, D. J. Introduction to Dislocations (Elsevier Science, 2011).

44. Ardell, A. J. Precipitation hardening. Metall. Trans. A 16, 2131-2165. https://doi.org/10.1007/BF02670416 (1985).

45. Chawla, M. A. M. K. K. Mechanical Behavior of Materials 2nd edn. (Cambridge University Press, 2008).

46. Olson, G. B. \& Cohen, M. A mechanism for the strain-induced nucleation of martensitic transformations. J. Less Common Metals 28, 107-118. https://doi.org/10.1016/0022-5088(72)90173-7 (1972).

47. Olson, G. B. \& Cohen, M. A general mechanism of martensitic nucleation: Part I. General concepts and the FCC $\rightarrow$ HCP transformation. Metall. Trans. 7, 1897-1904. https://doi.org/10.1007/BF02659822 (1976).

48. Rémy, L. \& Pineau, A. Twinning and strain-induced f.c.c. $\rightarrow$ h.c.p. transformation on the mechanical properties of $\mathrm{Co}-\mathrm{Ni}-\mathrm{Cr}-\mathrm{Mo}$ alloys. Mater. Sci. Eng. 26, 123-132. https://doi.org/10.1016/0025-5416(76)90234-2 (1976).

49. Lee, T.-H., Shin, E., Oh, C.-S., Ha, H.-Y. \& Kim, S.-J. Correlation between stacking fault energy and deformation microstructure in high-interstitial-alloyed austenitic steels. Acta Mater. 58, 3173-3186. https://doi.org/10.1016/j.actamat.2010.01.056 (2010).

50. Bouaziz, O., Allain, S., Scott, C. P., Cugy, P. \& Barbier, D. High manganese austenitic twinning induced plasticity steels: A review of the microstructure properties relationships. Curr. Opin. Solid State Mater. Sci. 15, 141-168. https://doi.org/10.1016/j.cossms. 2011.04.002 (2011).

51. Nishiyama, Z. Martensitic Transformation (Elsevier Science, 2012).

\section{Acknowledgements}

This work was supported financially by the Fundamental Research Program of the Korea Institute of Materials Science (PNK7570). This work was also supported by the Basic Science Research Program through the National Research Foundation of Korea funded by the Ministry of Science and ICT (NRF-2019R1A2C4070650) and (NRF-2019R1C1C1010246).

\section{Author contributions}

S.D.K. and T.H.L. designed the experiments and performed part of the microstructural characterizations. S.J.P. and J.H.S. performed preparation of specimens. C.H.L. and J.M. conducted testing of mechanical properties. H.P. and J.H.J. supported diffraction pattern analysis. S.D.K., H.Y.H. and T.H.L. analyzed data and wrote the paper. All authors discussed the results and commented on the manuscript.

\section{Competing interests}

The authors declare no competing interests.

\section{Additional information}

Supplementary Information The online version contains supplementary material available at https://doi.org/ 10.1038/s41598-021-93795-4.

Correspondence and requests for materials should be addressed to T.-H.L.

Reprints and permissions information is available at www.nature.com/reprints. 
Publisher's note Springer Nature remains neutral with regard to jurisdictional claims in published maps and institutional affiliations.

(c) (i) Open Access This article is licensed under a Creative Commons Attribution 4.0 International License, which permits use, sharing, adaptation, distribution and reproduction in any medium or format, as long as you give appropriate credit to the original author(s) and the source, provide a link to the Creative Commons licence, and indicate if changes were made. The images or other third party material in this article are included in the article's Creative Commons licence, unless indicated otherwise in a credit line to the material. If material is not included in the article's Creative Commons licence and your intended use is not permitted by statutory regulation or exceeds the permitted use, you will need to obtain permission directly from the copyright holder. To view a copy of this licence, visit http://creativecommons.org/licenses/by/4.0/.

(C) The Author(s) 2021 